\title{
REVIEW : ANALISIS PERAN TENAGA KESEHATAN DALAM KESIAPSIAGAAN MENGHADAPI BENCANA BANJIR DI KABUPATEN MALANG JAWA TIMUR
}

\author{
Review: Analysis Of The Role Of Health Personnel In Preparation For Flood \\ Disaster In Malang District, East Java \\ ${ }^{1}$ Lilis Sulistiya Nengrum

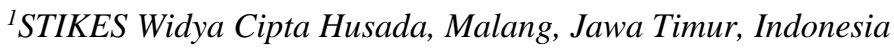 \\ *e-mail : lilissulistiya01@gmail.com
}

\begin{abstract}
ABSTRAK
Bencana adalah kejadian pada suatu daerah yang mengakibatkan kerusakan ekologi, kerugian kehidupan manusia serta memburuknya kesehatan dan pelayanan kesehatan yang bermakna sehingga memerlukan bantuan luar biasa dari pihak luar. Dalam keadaan bencana terdapat peran tenaga kesehatan untuk pelayanan kesehatan pada masyarakat dengan manajemen bencana yang di miliki. Tujuan penelitian ini adalah untuk menganalisis peran tenaga kesehatan dalam kesiapsiagaan menghadapi bencana banjir di Kabupaten Malang Jawa Timur. Desain penelitian yang digunakan adalah metode deskriptif dengan pendekatan cross sectional dengan sampel 107 responden. Hasil penelitian yang diperoleh menunjukan bahwa peran Tenaga Kesehatan dalam kesiapsiagaan menghadapi bencana banjir sebanyak 71 orang $(66,4 \%)$ memiliki peran yang cukup dan tenaga kesehatan yang memiliki peran baik berjumlah 21 orang (19,6\%). Adapun kesimpulan dari penelitian ini menunjukkan bahwa peran tenaga kesehatan mayoritas cukup,.diharapkan dengan adanya penelitian ini perlu ditingkatkan dalam peran tenaga kesehatan dalam manajemen bencana dan pelayanan bencana.
\end{abstract}

Kata kunci : Bencana Banjir, Peran, Tenaga Kesehatan

\section{ABSTRACT}

A disaster is in an area that results in ecological damage, loss of human life as well as deteriorating health and meaningful health services that require extraordinary assistance from outside parties. In a state of disaster, there is a role for health services in the community with disaster management. The purpose of this study was to analyze the role of health workers in flood disaster preparedness in malang regency, east java. The research design used is descriptive method with cross sectional approach, with a sample of 107 respondents. The research results obtained show that the role of health workers in flood disaster preparedness is 71 people $(66,4 \%)$ and 21 people $(19,6 \%)$ have a good role. As for the conclusion of this study, it shows that the role of the majority of health workers is sufficient. It is hoped that this reseatch needs to be increased in the role of health workers in disaster management and disaster services.

Keyword : Flood Disaster, Role, Health Personnel

\section{PENDAHULUAN}

World Health Organization (WHO), mendefinisikan bencana adalah Kejadian pada suatu daerah yang mengakibatkan kerusakan ekologi, kerugian kehidupan manusia serta memburuknya kesehatan dan pelayanan kesehatan yang bermakna sehingga memerlukan bantuan luar biasa dari pihak luar (Mizam, 2012). Undang - undang No. 24 tahun 2007 menyebutkan, pengertian dari bencana adalah Peristiwa atau rangkaian peristiwa yang mengancam dan mengganggu kehidupan dan penghidupan masyarakat yang disebabkan, baik oleh faktor alam dan/atau faktor non alam maupun faktor manusia 
sehingga mengakibatkan timbulnya korban jiwa manusia, kerusakan lingkungan, kerugian harta benda, dan dampak psikologis (Mizam, 2012).

Badan Nasional Penanggulangan Bencana (BNPB) mencatat 3.622 bencana terjadi di Indonesia sepanjang Januari 2019 sampai 16 Desember 2019. Secara umum, dari data tersebut terjadi kenaikan jumlah bencana jika dibandingkan dengan beberapa tahun ini, artinya sepanjang 2009-2019 terjadi peningkatan bencana dimana antaranya meliputi bencana banjir, puting beliung paling yang setiap tahunnya semakin meningkat. Badan Nasional Penanggulangan Bnecana (BNPB) 2019, juga mencatat Jawa Tengah sebagai provinsi dengan jumlah bencana terbanyak yang mencapai 859 kejadian, kemudian diikuti oleh Jawa Barat 672 kejadian, dan Jawa Timur dengan 582 kejadian berada diuruatan ketiga, sedangkan aceh dengan 117 kejadian dan Sulawesi Selatan 162 kejadian (BNPB, 2019).

Badan Penanggulangan Bencana Daerah (BPBD) Kabupaten Malang, mencatat di tahun 2018 lalu sebanyak 71 bencana alam didominasi oleh banjir dan longsor. Pada awal tahun 2020 berbagai peristiwa banjir telah terjadi di wilayah kabupaten Malang Selatan yang menjadi langganan setiap tahunnya (BPBD, 2020). Dampak yang ditimbulkan akibat bencana yang merupakan suatu kejadian yang tidak diinginkan dan biasanya terjadi secara mendadak serta menimbulkan korban jiwa. Salah satu kendala yang sering dijumpai dalam penanggulangan krisis di daerah bencana adalah kurangnya Sumber Daya Manusia (SDM) (Yunia, 2018).

SDM atau Tenaga kesehatan untuk pelayanan kesehatan pada kejadian bencana sangat perlu untuk memperhatikan kompetensi manajemen bencana yang dimiliki SDM kesehatan setempat khususnya yang bertugas di Pusat Kesehatan Masyarakat (Puskesmas), terutama daerah rawan bencana, khususnya daerah kabupaten kepanjen yang setiap tahunnya terjadinya bencana banjir, sehingga peran tenaga kesehatan sangat dibutuhkaan untuk meminimalisir kerugian akibat bencana yang terjadi, disisi lain peran tenaga kesehatan juga dibutuhkan yang tanggap dan siap dalam penanggulanggan bencana (Susilawati, 2019). Pusat Kesehatan Masyarakat (Puskesmas) merupakan salah satu tempat pelayanan kesehatan yang dijadikan pusat pelayanan khususnya ketika terjadi bencana banjir. Hal ini sejalan dengan yang di jelaskan oleh BNPB pada tahun 2015, bahwa puskesmas memiliki peran aktif dalam meningkatkan keterlibatan masyarakat dalam upaya penanggulangan bencana sebagai unit pelayanan kesehatan terdekat di masyarakat (BNPB, 2015).

Puskesmas bertugas untuk memberikan pelayanan kesehatan saat krisis bencana dengan melakukan berbagai kegiatan seperti pelayanan gawat darurat 24 jam, pendirian pos kesehatan 24 jam di sekitar lokasi bencana, upaya gizi, Kesehatan Ibu dan Anak (KIA) dan sanitasi pengungsian, upaya kesehatan jiwa serta upaya kesehatan rujukan sesaat setelah terjadinya bencana (Depkes, 2007). Tenaga kesehatan di puskesmas memiliki peran penting untuk mempersiapkan kelompok rentan pada fasefase bencana khususnya dalam penanggulan bencana, sehingga tenaga kesehatan perlu untuk membekali diri dengan skill manajemen bencana yang baik (Susilawati, 2019).

Berdasarkan hasil studi pendahuluan yang telah dilakukan kepada pihak tenaga kesehatan menjelaskan bahwa di desa Sitiarjo setiap tahunnya terjadi bencana banjir yang selalu berulang saat musim hujan, sebagai petugas kesehatan memiliki peran yang penting ketika terjadinya bencana banjir, akan tetapi sejauh ini tingkat penegtahuan atau kesiapan serta peran petugas kesehatan tidak pernah dilakukan evaluasi atau penelitian. Artinya pengetahuan dan peran tenaga kesehatan dalam penanggulan bencana banjir itu baik atau kurang sehingga perlunya adanya penelitian ini. Oleh karena itu, berdasarkan uraian di atas, peneliti tertarik untuk melakukan penelitian tentang "Analisis peran tenaga kesehatan dalam kesiapsiagaan menghadapi bencana banjir di Kabupaten Malang Jawa Timur"

\section{METODE PENELITIAN}

Jenis penelitian yang digunakan adalah deskriptif menggunakan pendekatan cross sectional dengan tujuan untuk mengetahui Analisis peran tenaga kesehatan dalam kesiapsiagaan menghadapi bencana banjir di Kabupaten Malang Jawa Timur.

\section{PEMBAHASAN}


Tabel 1.Distribusi frekuensi responden berdasarkan jenis kelamin $(n=107)$.

\begin{tabular}{ccc}
\hline & Frekuensi & $\mathbf{( \% )}$ \\
\hline Laki Laki & 50 & $46.7 \%$ \\
Perempuan & 57 & $53.3 \%$ \\
\hline Total & $\mathbf{1 0 7}$ & $\mathbf{1 0 0 \%}$ \\
\hline
\end{tabular}

Tabel 2. Distribusi frekuensi responden berdasarkan pendidikan. $(\mathrm{n}=107)$.

\begin{tabular}{ccc}
\hline Pendidikan & Frekuensi & $\mathbf{( \% )}$ \\
& & \\
\hline D3 & 65 & $60.7 \%$ \\
S1 & 42 & $39.3 \%$ \\
S2 & 0 & $0 \%$ \\
S3 & 0 & $0 \%$ \\
\hline Total & $\mathbf{1 0 7}$ & $\mathbf{1 0 0 \%}$ \\
\hline
\end{tabular}

\section{Peran Tenaga Kesehatan dalam kesiapsiagaan menghadapi bencana banjir di Kabupaten Malang}

Tabel 4. Hasil distribusi frekuensi responden berdasarkan perantenaga keseahtan $(n=107)$.

\begin{tabular}{|c|c|c|c|c|c|}
\hline \multirow[t]{2}{*}{ Variabel } & \multicolumn{2}{|c|}{ Kriteria/Skor } & \multirow{2}{*}{$\begin{array}{l}\mathbf{N} \\
21\end{array}$} & \multirow{2}{*}{$\begin{array}{l}(\%) \\
19.6 \%\end{array}$} & \multirow[t]{2}{*}{ Mean } \\
\hline & $\begin{array}{l}\text { Baik } \\
30\end{array}$ & $25-$ & & & \\
\hline \multirow[t]{2}{*}{ Peran } & $\begin{array}{l}\text { Cukup } \\
24\end{array}$ & $20-$ & 71 & $66.4 \%$ & 22,96 \\
\hline & $\begin{array}{l}\text { Kurang } \\
19\end{array}$ & $15-$ & 15 & $14.0 \%$ & \\
\hline \multicolumn{3}{|c|}{ Total } & 107 & $100 \%$ & \\
\hline
\end{tabular}

Sumber data : Data Primer Juli 2020

Hasil Penelitian ini menunjukan bahwa peran Tenaga Kesehatan dalam kesiapsiagaan menghadapi bencana banjir sebanyak 71 orang $(66,4 \%)$ memiliki peran cukup dan tenaga kesehatan yang memiliki peran baik berjumlah 21 orang $(19,6 \%)$.

Peran adalah aspek dinamis dari kedudukan atau status. Menurut Kozier peran adalah seperangkat tingkah laku yang diharapkan oleh orang lain terhadap seseorang sesuai kedudukannya dalam, suatu system. Peran dipengaruhi oleh keadaan sosial baik dari dalam maupun dari luar dan bersifat stabil. Peran adalah bentuk dari perilaku yang diharapkan dari seseorang pada situasi sosial tertentu. Peran menjadi bermakna ketika dikaitkan dengan orang lain. Penelitian ini menunjukkan bahwa peran tenaga kesehatan terkait kesiapsiagaan bencana banjir dapat tergolong cukup, dimana tenaga kesehatan yang memiliki peran baik hanya berjumlah $21(19,6 \%)$ orang, dimana hasil ini mennunjukkan bahwa dengan tenaga kesehatan yang berpendidikan tinggi memiliki peran baik, hal ini sejalan dengan hasil penelitian Indri Setiawati, (2020) mengatakan bahwa pendidikan sangat berpengaruh terhadap terwujudnya kesiapsiagaan bencana (Kurniawati \& Suwito, 2017). Fungsi pendidikan merupakan salah satu media terbaik untuk mempersiapkan segala hal, Peran tenaga kesehatan di lingkup daerah yang rawan bencana banjir sangat lah dibutuhkan, banyak faktor penyebab yang dapat mempengaruhi peran tenaga kesehatan dalam kesiapsiagaan menghadapi bencana khususnya banjir, seperti kurangnya fasilitas dan tenaga kesehatan dimana bekerja tidak sesuai tupoksi masing masing tenaga kesehatan, hal ini sejalan dengan hasil penelitian Lestari (2012), menyebutkan bahwa fasilitas, pendidikan, tenaga kesehatan atau SDM merupakan salah satu faktor penyebab kurangnya peran tenaga kesehatan.

Ada banyak peran tenaga kesehatan terkait bencana banjir yaitu tenaga kesehatan mengikuti pelatihan dan pendidikan yang berhubungan dengan penanggulangan bencana untuk tiap fasenya, tenaga kesehatan ikut terlibat dalam berbagai dinas pemerintah, organisasi lingkungan, palang merah nasional, maupun lembaga-lembaga kemasyarakatan dalam memberikan penyuluhan dan simulasi persiapan menghadapi bencana, tenaga kesehatan terlibat dalam program promosi kesehatan untuk meningkatkan kesiapan masyarakat dalam menghadapi bencana banjir (Setiawati,2020). Oleh karena itu peran tenaga kesehatan khususnya perawat dalam kesiapsiagaan dalam mengahdapi bencana banjir, dengan tujuan meningkatkan pelayanan kesehatan terhadap masyarakat di tingkatkan kembali, agar lebih baik, dimana bisa terlibat dalam kesipasiagaan bencana banjir.

\section{KESIMPULAN}




\begin{abstract}
Berdasarkan hasil penelitian dapat disimpulkan,Sebanyak 71 orang $(66,4 \%)$ memiliki peran cukup dan tenaga kesehatan yang memiliki peran baik berjumlah 21 orang $(19,6 \%)$ dalam kesiapsiagaan menghadapi bencana banjir di puskesmas Desa Sitiarjo Kabupaten Malang. Hal ini dikarenakan banyak faktor penyebab yang dapat mempengaruhi peran tenaga kesehatan dalam kesiapsiagaan menghadapi bencana khususnya banjir, seperti kurangnya fasilitas dan tenaga kesehatan dimana bekerja tidak sesuai tupoksi masing masing tenaga kesehatan.

Disarankan dengan adanya penelitian ini diharapkan dapat menjadi masukan bagi pelayanan kesehatan untuk dapat meningkatkan peran dan perilaku yang baik, dengan cara mencari informasi melalui berbagai media tentang kesiapsiagaan dalam menghadapi bencana banjir yang benar dan tepat serta merubah peran kurang agar lebih baik lagi, serta terlibat dalam kesiapsigaan bencana banjir.Disarankan untuk peneliti selanjutnya bisa menggunakan variabel sikap dan perilaku tenaga kesehatan.
\end{abstract}

\section{DAFTAR PUSTAKA}

Arikunto, S. (2010). Prosedur Penelitian: Suatu Pendekatan Praktik (Edisi Refisi). Jakarta: Rineka Cipta.

BNPB. (2015). Rencana Strategis BNPB Tahun 2015-2019. Badan Penanggulangan Bencana Republik Indonesia. www.bnpb.go.id

BNPB. (2017). Badan Penanggulangan Bencana.

BNPB RI. (2007). Undang-Undang Republik Indonesia Nomor $24 \quad$ Tahun 2007 Tentang Penanggulangan Bencana. Retrieved from https://bnpb.go.id/uploads/migration/pubs/1.p df

Budiman \& Riyanto A. 2013. Kapita Selekta Kuisioner Pengetahuan Dan Sikap. Dalam Penelitian Kesehatan. Jakarta : Salemba Medika pp 6669

Depkes. (2007). Pedoman Teknis Penanggulangan Krisis Kesehatan Akibat Bencana.
Dougherty \& Pritchard. 6. Abu Ahmadi, Psikologi Sosial, )Jakarta:Pt. Rineka Cipta,1991), hlm. 255. 7. Roderick Martin, 1993, Sosiologi Kekuasaan. (Jakarta: Pt 2018

Dhjauhari, N. (2014). Pengantar Mitigasi bencana (Edisi Pert). Yogyakarta.

Fakhrurrazi, M. (2015). Pengetahuan Dan Sikap Tenaga Kesehatan Rumah Sakit Umum Daerah ( Rsud ) Pidie Jaya Terhadap Kesiapsiagaan Dalam Menghadapi Risiko Bencana. 2014, 1-12.

Undang-undang RI NO.36 tahun 2014. Tentang tenaga kesehatan , Kemnetrian Kesehatan Republik Indonesia

Notoadmojo. (2012). Metode penelitian Kesehatan. (Revisi, Ed.). Jakarta.nt. Urnal ilmiah kesehatan media husada, 85-92.

Nurjannah, S. (2013). Menejemen Bencana. Bandung: ALfabeta.

Suhartono. (2015). Filsafat Ilmu Pengetahuan: Persoalan Eksistensi dan Hakikat Ilmu Pengetahuan. (Yogyakarta, Ed.). Ar-Ruz Media.

Setiawati, I. (2020) 'Gambaran pengetahuan dan sikap perawat tentang kesiapsiagaan pelayanan kesehatan dalam menghadapi bencana banjir', 10(2).

Susilawati, A. (2019). Indonesian Journal Of Community Health Nursing ( Jurnal Keperawatan Komunitas ) ( Description Preparedness of Health Workers in Disaster Management in Public Health Center. 8(1), 11-16. 